\title{
B. Übersicht über die Finanz- und Handelsströme zwischen der Schweiz und den Entwicklungs-und Transitionsländern
}

\section{Gérard Perroulaz and Xavier Tschumi Canosa}

\section{(2) OpenEdition Journals}

Electronic version

URL: http://journals.openedition.org/sjep/169

ISSN: 1663-9677

Publisher

Institut de hautes études internationales et du développement

\section{Printed version}

Date of publication: 1 avril 2006

Number of pages: $231-241$

ISBN: 2-88247-062-2

ISSN: $1660-5926$

\section{Electronic reference}

Gérard Perroulaz und Xavier Tschumi Canosa, « B. Übersicht über die Finanz- und Handelsströme zwischen der Schweiz und den Entwicklungs-und Transitionsländern », Schweizerisches Jahrbuch für Entwicklungspolitik [Online], 25-1 | 2006, Online erschienen am: 19 April 2010, abgerufen am 07 September 2020. URL : http://journals.openedition.org/sjep/169 
B. Übersicht über die Finanz- und Handelsströme zwischen der Schweiz und den Entwicklungsund Transitionsländern 


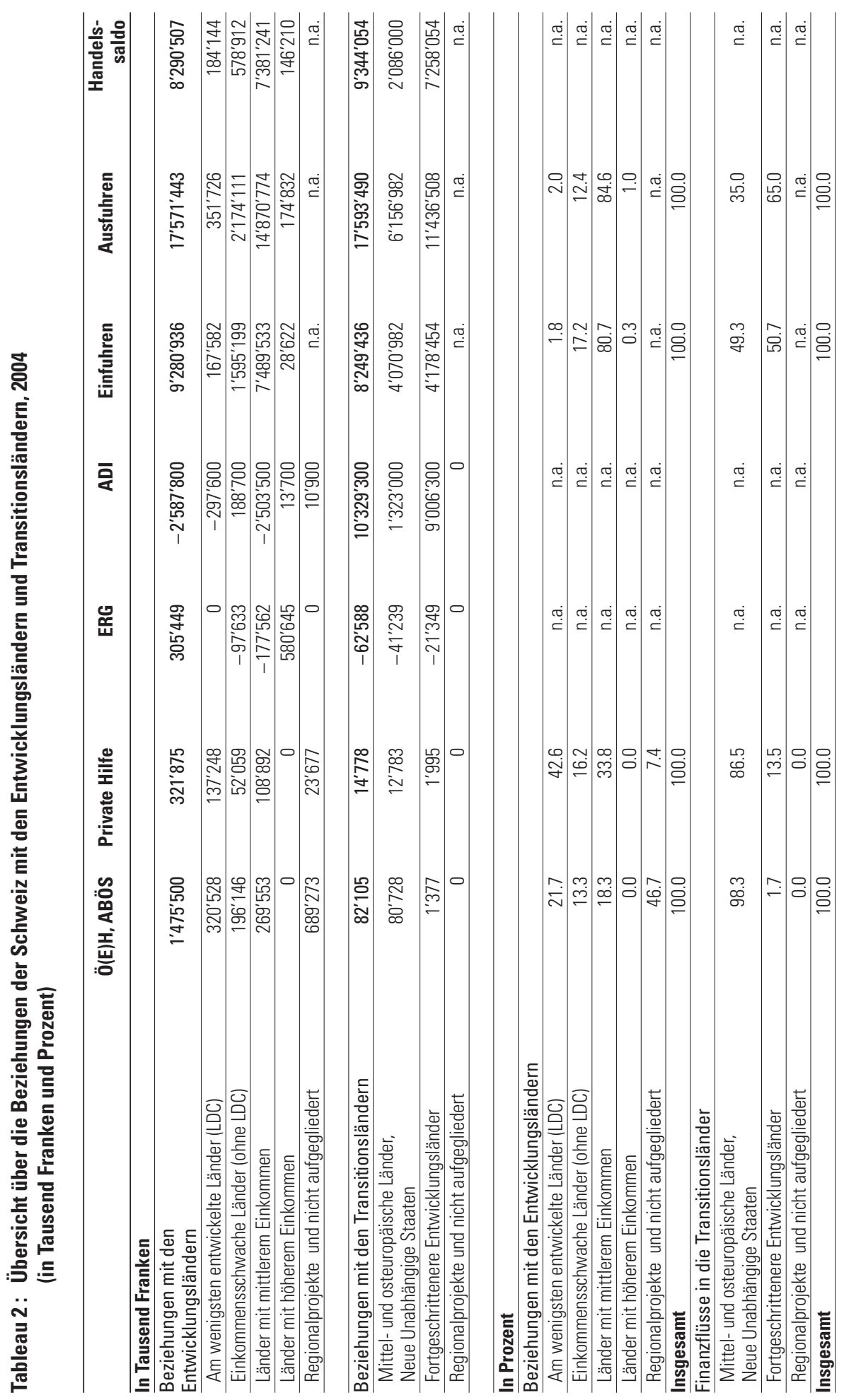



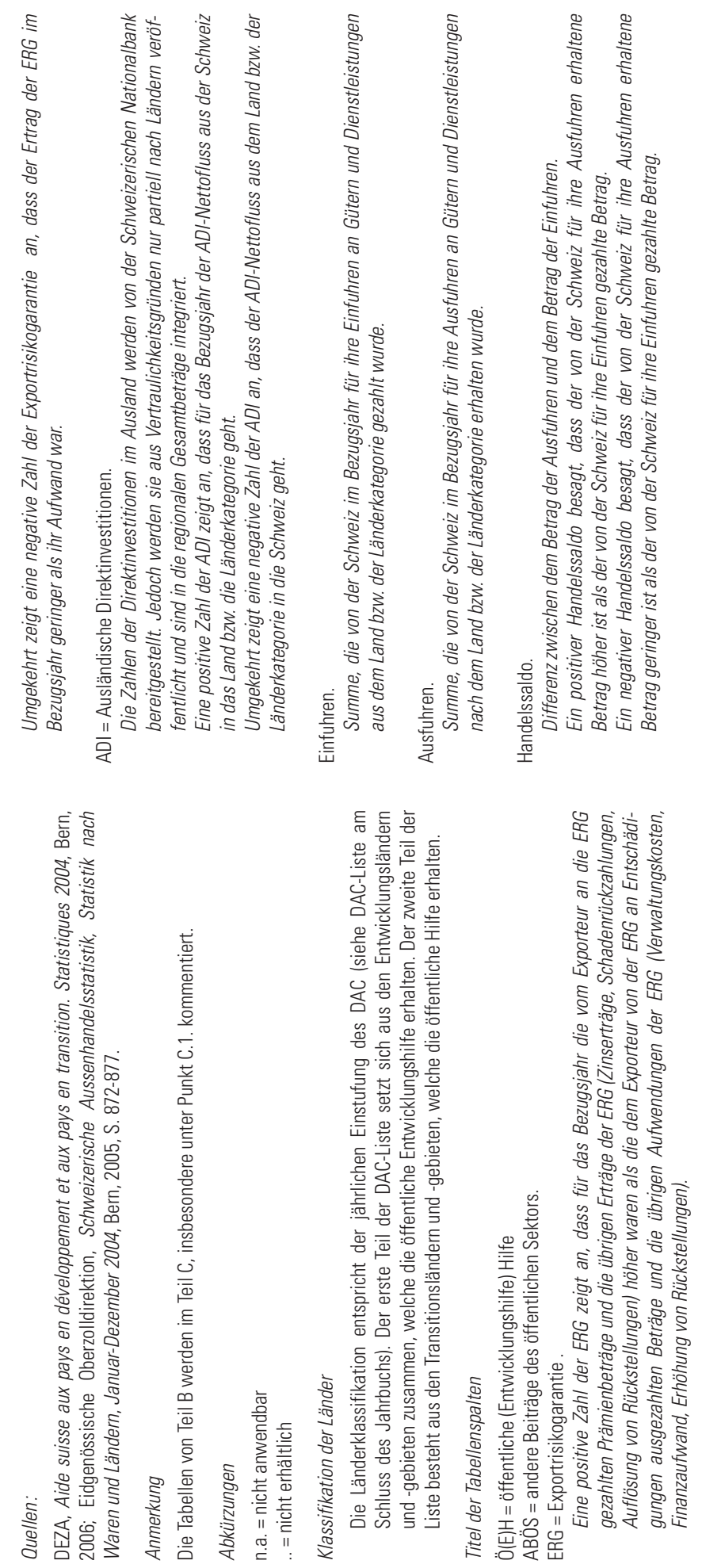


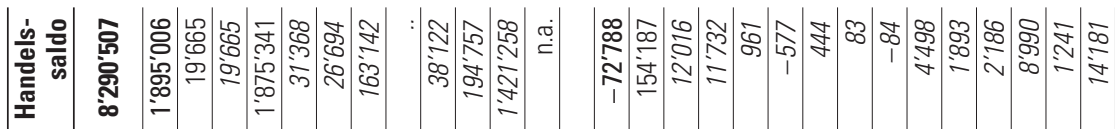

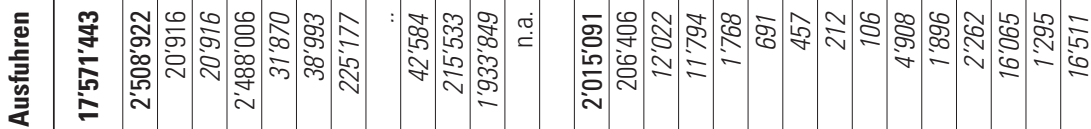

흔

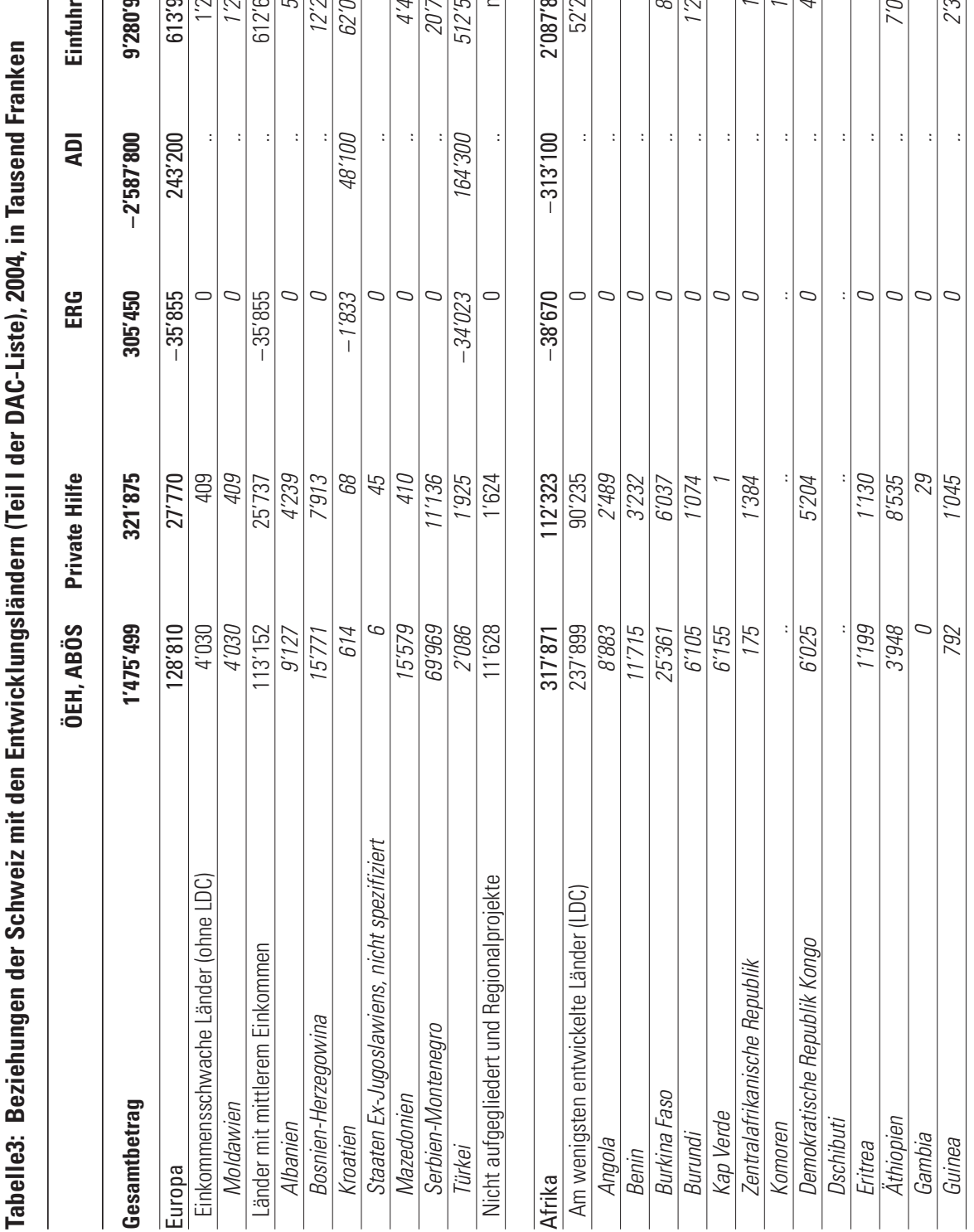




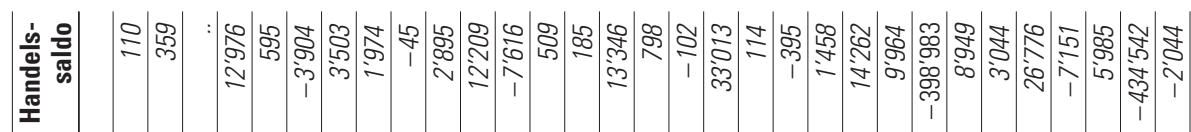

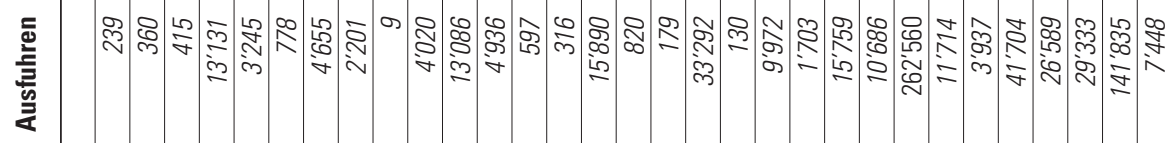

言旁

高

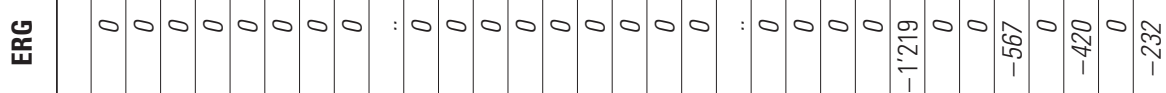

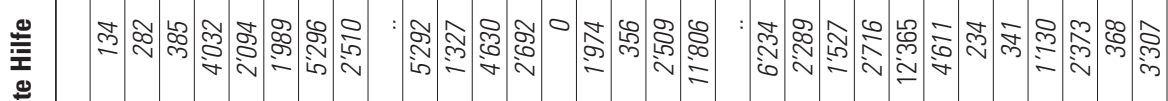

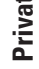

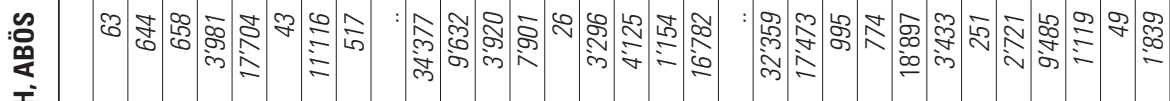
풍

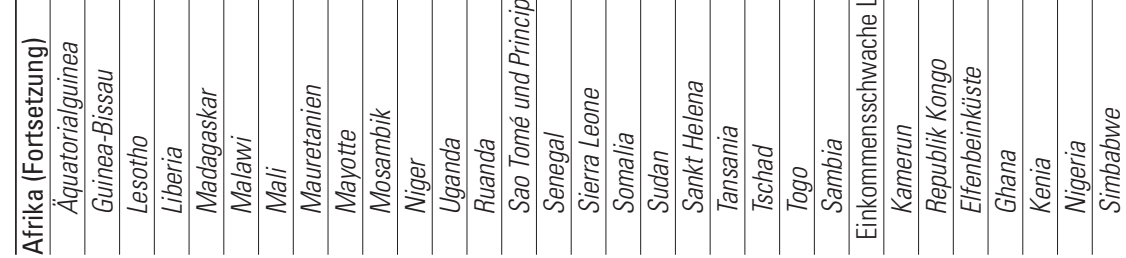




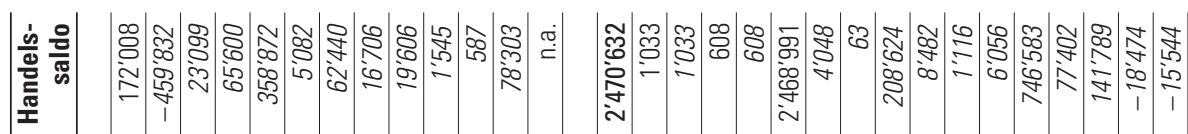

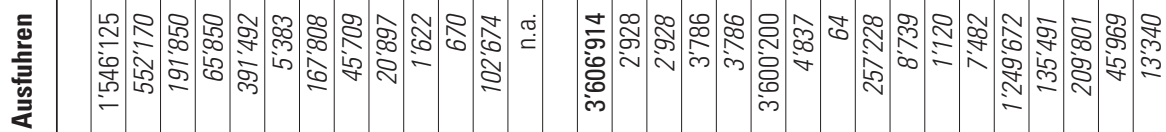

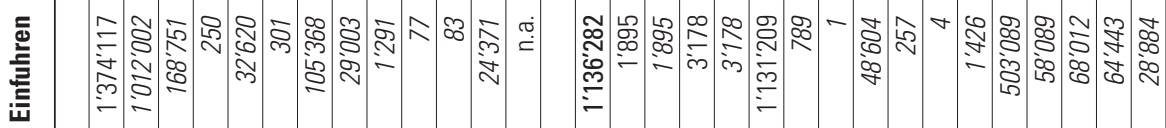

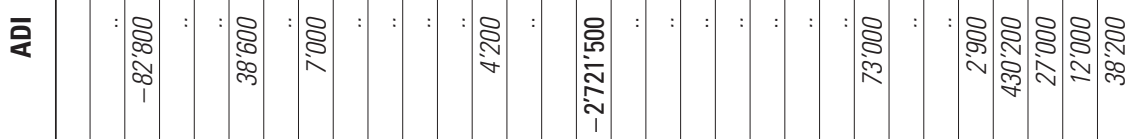

要

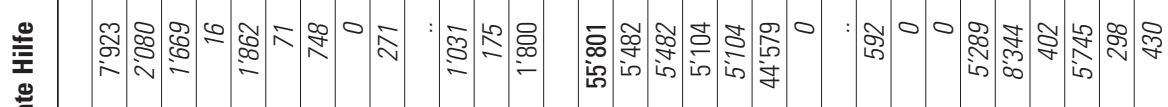

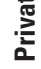

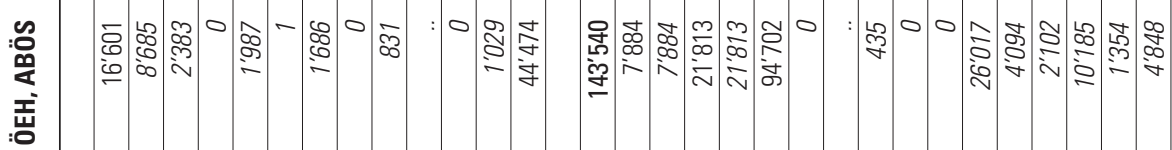

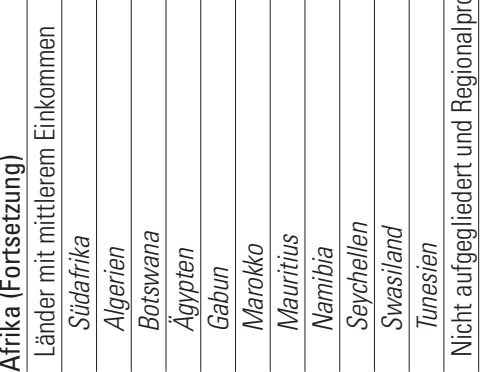

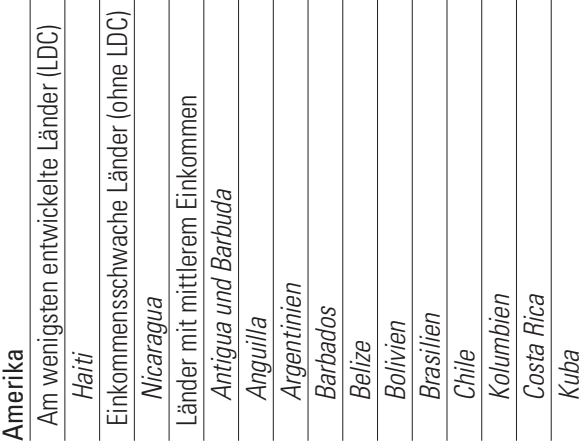




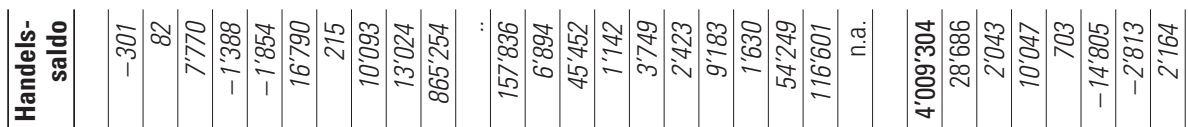

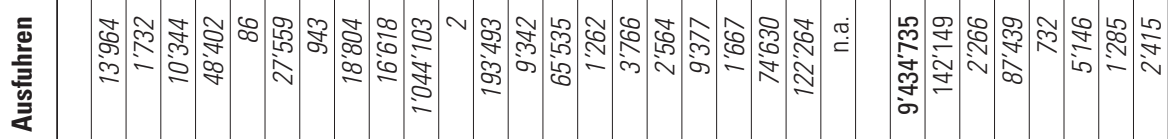

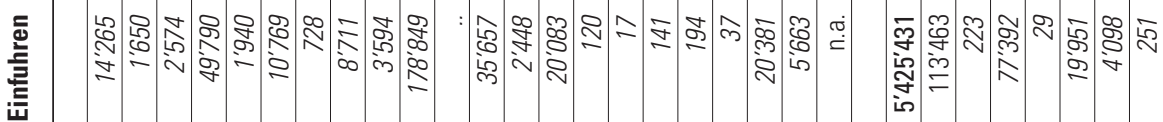

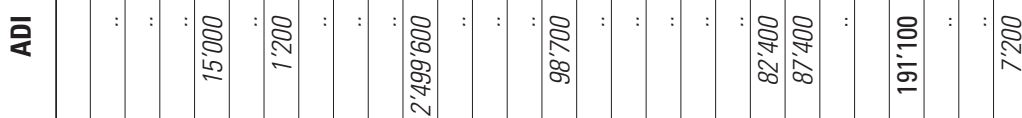

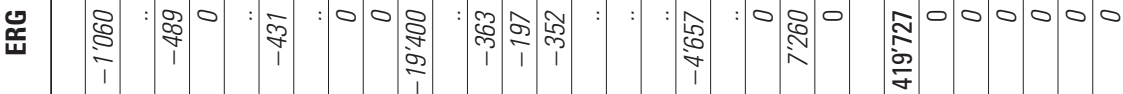

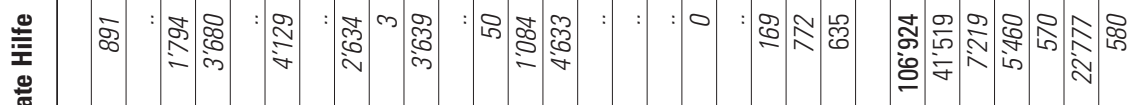

离

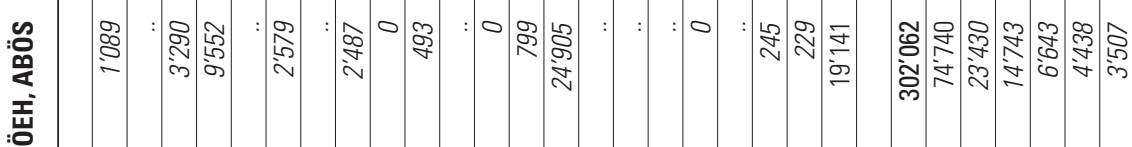

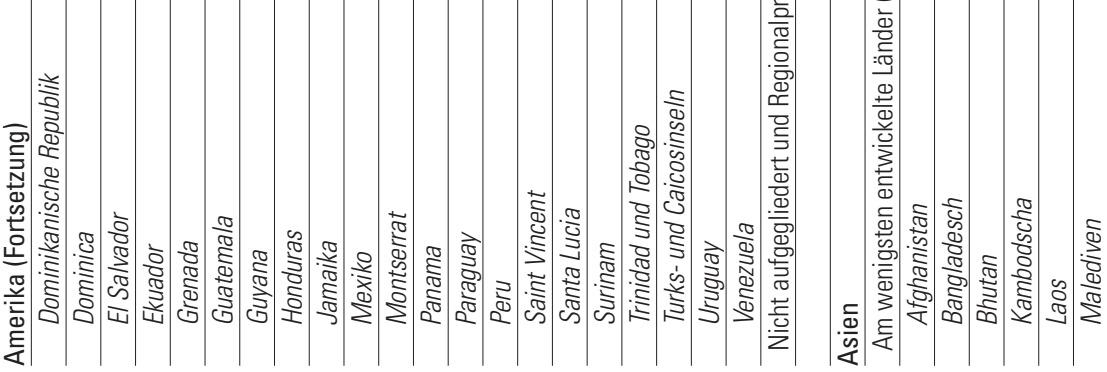




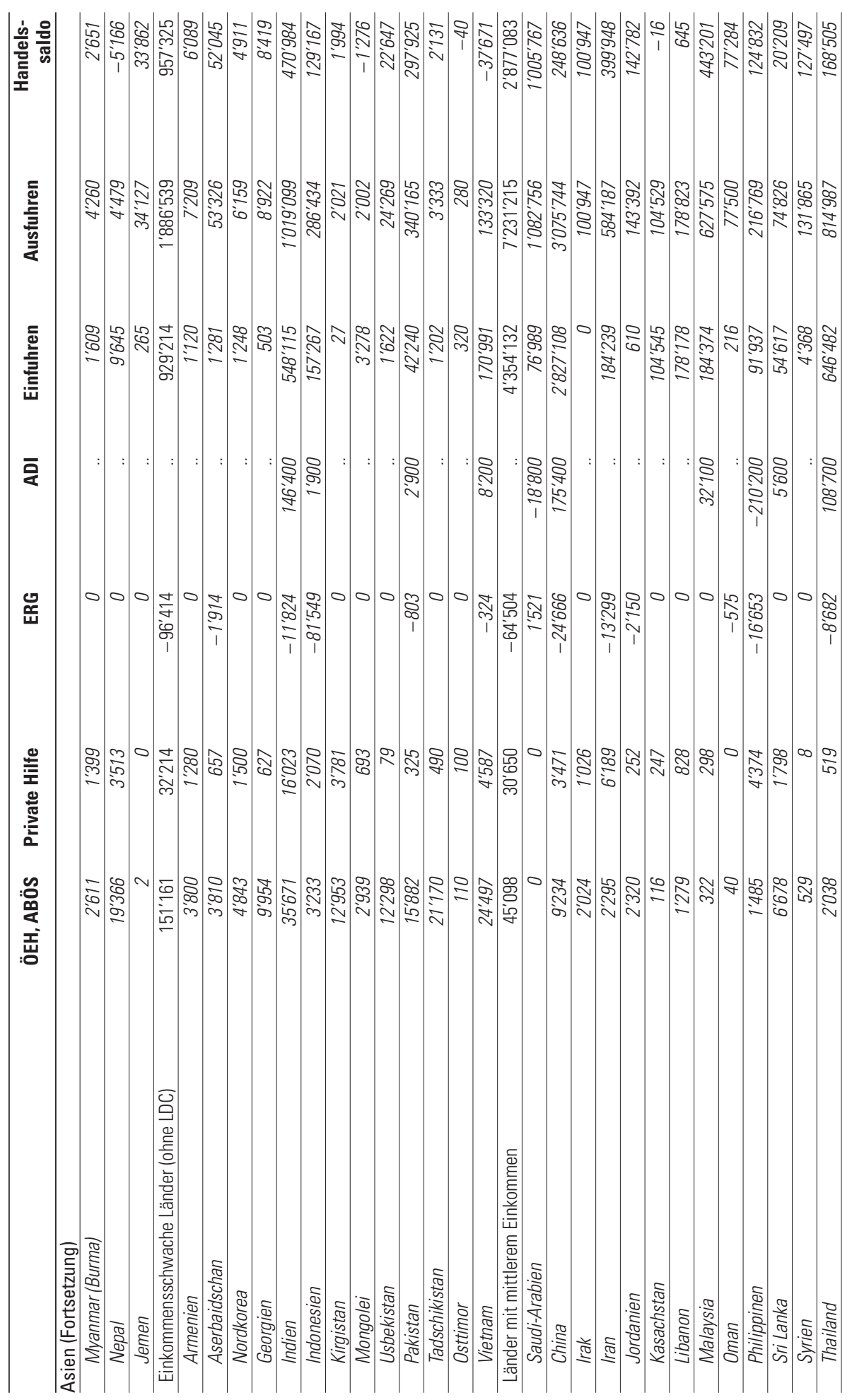




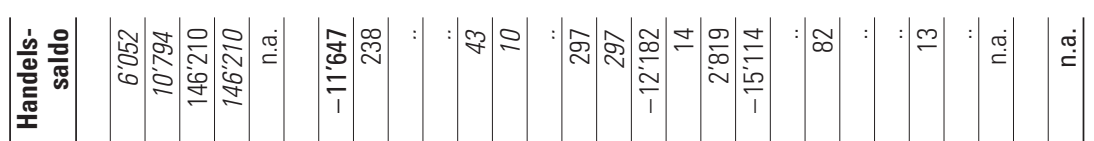

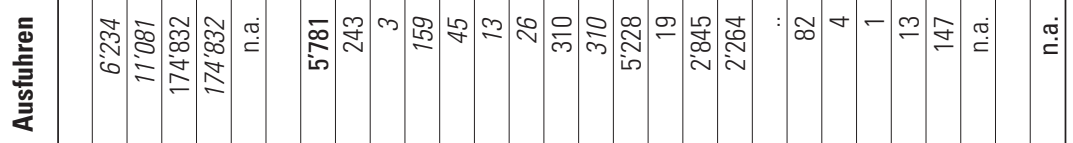

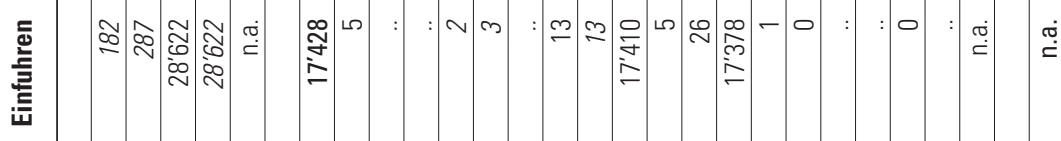

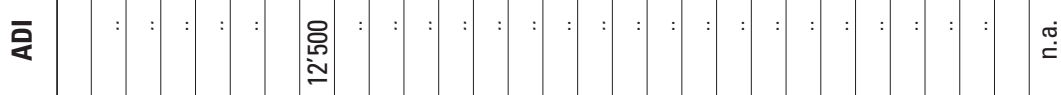

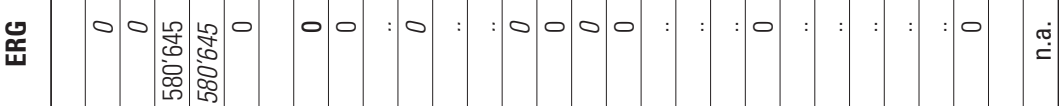

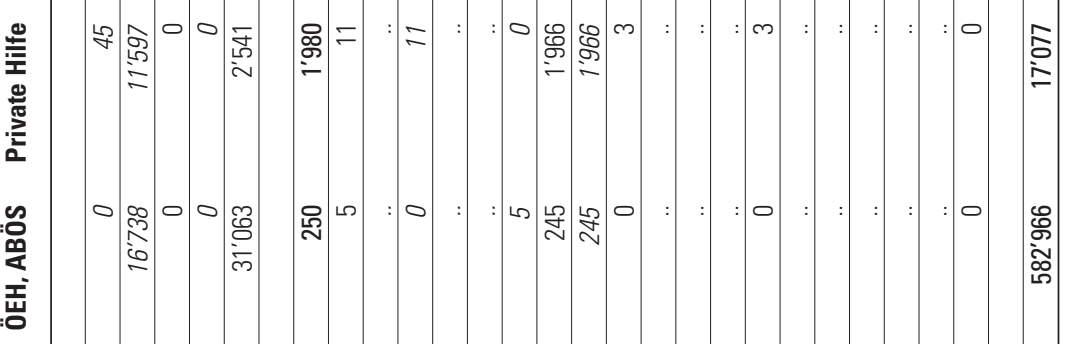

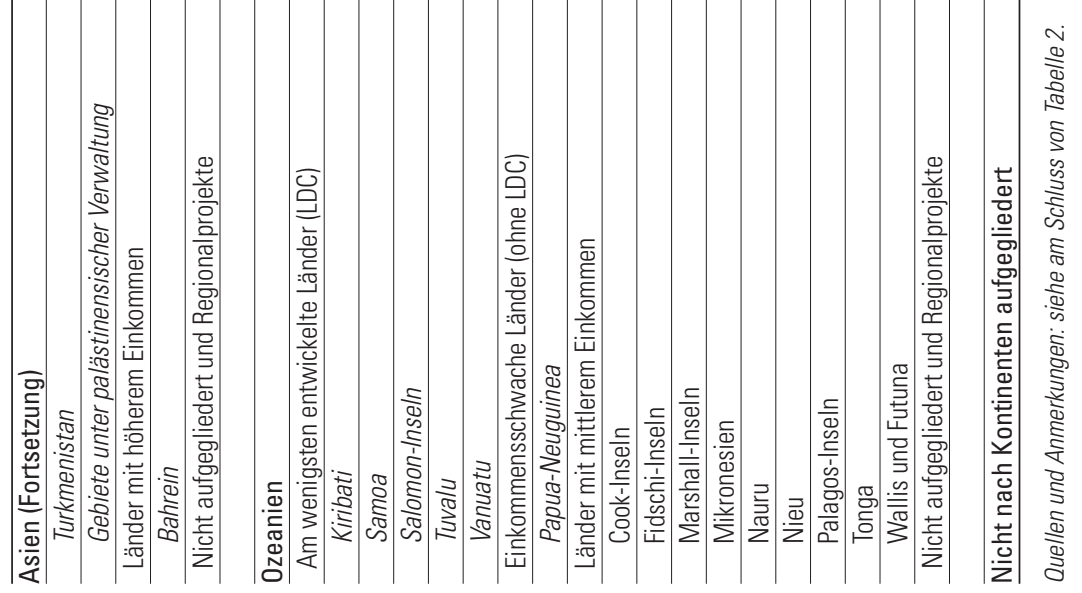




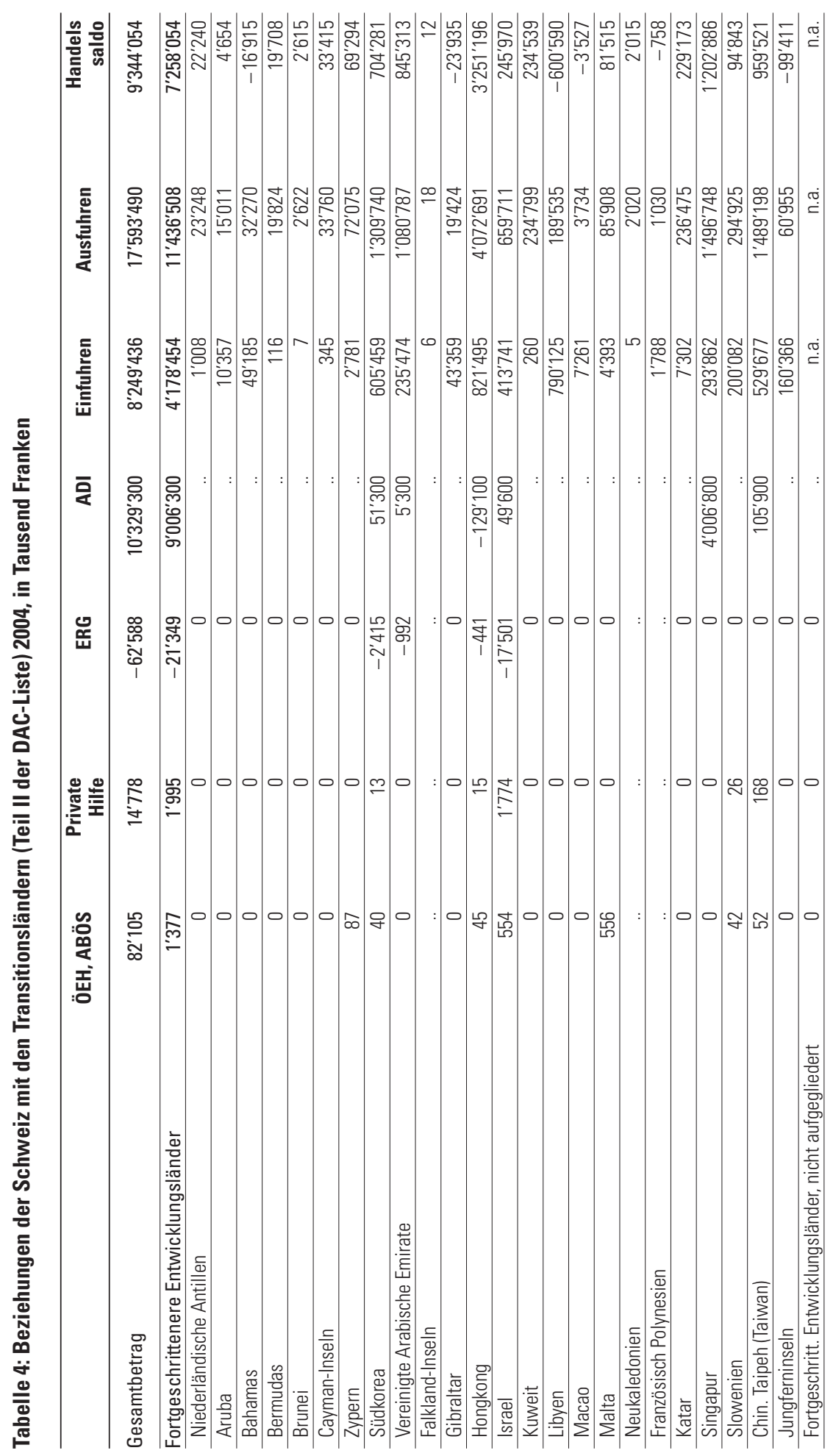




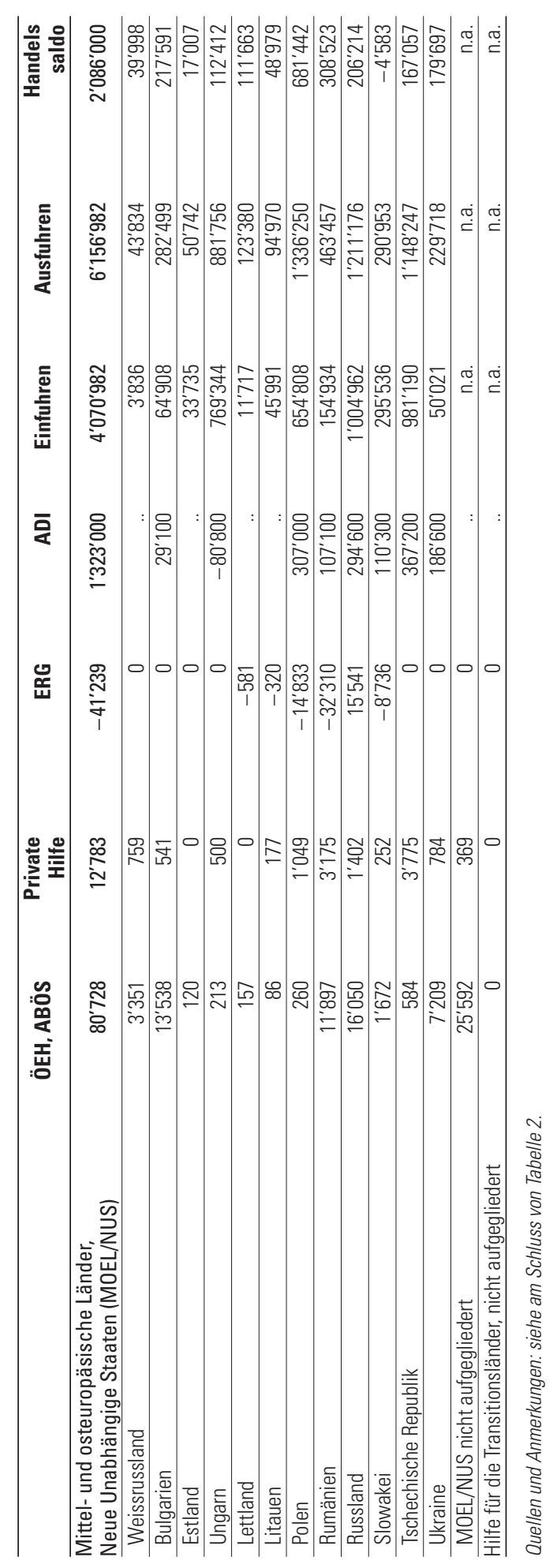


